\title{
Internationalization of Research Capacity Building in Africa: A Case Study of Swedish International Development Authority (SIDA) Support for Addis Ababa (AAU) and Dar-Es-Salaam (UDSM) Universities
}

\author{
Teshome Nekatibeb Begna \\ Center of Comparative Education and Policy Studies, Addis Ababa University, Ethiopia
}

\begin{abstract}
Africa has realized the need to strengthen its research capacity to meet the demands for development and economic prosperity. However, this effort must take place under a heavy pressure for financial, highly qualified human and other resources. Governments on the continent devote quite significant parts of their budget in higher education; but most of it goes to teaching. Under these circumstances, research is left with small allocations or to funding from international donors. SIDA (Swedish International Development Authority) is one of such donors which has been involved in funding Addis Ababa and Dar-Es- Salaam Universities in Ethiopia and Tanzania respectively. The purpose of this study was to explore the effectiveness of SIDA support in both universities in terms of research capacity building. A meta-analytical case study approach which used qualitative instruments was applied to collect data. Findings indicate that SIDA support in both institutions contributed to institutional capacity building in research and research training. Both institutions reported that productivity in research and the likelihood of the number of students graduating with research degrees as well as the number of graduate programs which enroll graduate students are expanding with SIDA support. Moreover, it was reported that Swedish support has helped to strengthen research management and infrastructure. The study also revealed that outstanding implementation issues obstructed the achievement of some of the anticipated outcomes of the agreements between SIDA and the universities. From these findings, it was implied that development aid makes contributions to solving problems faced by developing countries, but it is not a sufficient condition to bring total change.
\end{abstract}

Keywords: Internationalization, Research, Research Capacity Building, Aid Effectiveness

\section{INTRODUCTION}

Since the past half century, academic systems around the world have been experiencing rapid and complex transformations to the extent that one can talk of "academic revolutions" (Altbach, Reisburg, Rumbley, 2009). Arguably, one of the most significant developments involves the globalization and internationalization of higher education with respect to research and research capacity building. According to Altbach (2006), globalization typically refers to the broad economic, technological and scientific trends that directly affect higher education and are largely inevitable in the contemporary world. Internationalization, on the other hand, has more to do with the specific policies and programs undertaken by governments, academic systems and institutions, and even individual departments to deal with globalization. The key difference between the concepts lies in the notion of control. Globalization and its effects are beyond the control of any one actor or set of actors. Internationalization, however, is a strategy for societies and institutions to respond to the many demands placed upon them by globalization and as a way for higher education to prepare individuals for engagement in a globalized world (Altbach, 2006).

The internationalization of higher education manifests itself in the movement of programs, knowledge, products and people among institutions. It is also noted with the rising prominence of collaborative research, evolution of curricula and new methods of teaching-learning systems and a sense of connectedness with the global system of higher education. Research is the practice of producing new knowledge. Research capacity building involves the preparation of the next generation of researchers as well as the creation of an enabling institutional environment for research training. The transition of the university from mainly a teaching institution of undergraduates to a research 
institution began in the $19^{\text {th }}$ century in Germany. Since then, research and innovation have achieved greater legitimacy in society through the use of knowledge for economic and social development, and the employment of university graduates in strategic positions in the private and public sectors (Clark, 1983; Altabach, Reisberg, Rumbley, 2009, Knight, 2006).

The modern university in Africa, which inherited most of its features from the European University, has been expanding over the last few decades. Damtew Tefera (2006) indicates that Nigeria, Sudan, South Africa and Egypt have 45, 26,21 and 17 universities respectively; and each country has many additional postsecondary institutions as well. Overall, the continent maintained its public investment in higher education for the last several years, allocating approximately 0.78 percent of its GDP and around $20 \%$ of its current public expenditure (AU, 2012). During this period, the total number of students pursuing higher education tripled, climbing from 2.7 million in 1991 to 9.3 million in 2006 (AU, 2012). This was an annual average growth rate of 16 percent. The total number of African universities is estimated to be 1,500 (AU, 2012). According to Damtew Teferaa (2006), the central reality for all African higher education system is the severe financial crises. This phenomenon relates to many factors, but mainly the pressures of expansion have made it difficult to put adequate or increased funding in the sector. The bulk of funding (90 to 95\%) is generated from state resources and this is devoted mostly to teaching. Research is the most underfunded function of the university and it is mostly funded by international donors. For a prolonged period, one of the most visible international donors in African higher education regarding research is the Swedish international Development Authority (SIDA). SIDA supports different universities in Africa, but the purpose of this study is to explore the contributions of SIDA funding to Addis Ababa and Dar-Es-Salaam Universities.

\section{Statement of the Problem}

Ethiopia is a good case in Africa where the growth of universities jumped from 2 in the 1980s to 34 full-fledged public and private universities in less than two decades. The GER in higher education has risen from $1.5 \%$ in 2009 to $9.5 \%$ in 2011/12. In Africa, the tertiary growth rate increased from $9 \%$ in 2006 to $10 \%$ in 2009 (MOE, 2011/12). Tanzania which earned its independence in 1961 has also experienced the expansion of higher education in recent years. At independence, the country had only one institute of higher learning (Ardhi Institute established 1956) whereas now it has 11 public and 17 private universities.

Addis Ababa University (AAU) is the oldest university in Ethiopia and it is aspiring to turn into a research university. This aspiration has its roots in Higher education proclamation 651/2009: "any public institution endowed with better postgraduate resources shall assist in the staff development of less so endowed public institutions". Similarly, the University of Dar- Es- Salaam (UDSM) is not only the oldest(established in 1961) and the largest in Tanzania, but also an aspirant institution to become a research university of high repute in Africa. However, both universities have limited capacities to become research intensive both in terms of researcher training and in carrying out high quality research. Due to this, they are heavily funded by SIDA (Swedish International Development Agency) to attract international technical and scientific assistance from Swedish and other universities.

The primary purpose of this study was to explore the process of how these universities having diverse backgrounds have built in-home research capacity and improved research training using international partnership with SIDA to meet rising demands for higher learning. Secondly, it was to provide a bird's eye view of the achievements of this collaboration in terms of creating researcher capital and institutional capacity. Third, the study will identify challenges to implementation of the research collaboration in the two universities and draws lessons for further improvement.

\section{OBJECTIVES OF THE STUdY}

The main objective of this study is to explore the effectiveness of development aid with regard to research and research capacity building in Africa by taking the case of SIDA institutional capacity support programs at Addis Ababa and Dar-Es-Salam Universities in Ethiopia and Tanzania respectively. The specific objectives of the study are:

- To analyze the contributions of SIDA for research capacity development in AAU/UDSM in terms of reach capacity building frameworks, funding, infrastructure, and integration of gender.

- To explore the implementation of SIDA support with focus on initialization of research, research management, structures and processes, result monitoring and management, grants and intellectual property management. 
- To describe research training in term of procedures of student selection and admission, joint research and supervision, training out puts, perceived impacts and utilization of outputs.

- Identify key barriers of implementation and draw lessons for future improvement of the collaboration.

\section{BASIC RESEARCh QUESTIONS}

- What is the extent to which SIDA support contributed to the formation of research capacity building framework in the two universities?

- To what extent and how does SIDA funding influenced the implementation of research and research training programs in terms of inputs, processes, outcomes as well as utilization of outcomes?

- What were the barriors for implementing SIDA support programs as originally anticipated in agreements?

- What are the lessons learned for future collaboration between SIDA and the two universities?

\section{Theoretical Perspectives}

\subsection{Internationalization of Higher Education}

Although higher education has been international in its history (see Clark, 1983, Perkins, 2006), it is now playing dynamic and extending broad. Detail analysis of internationalization in higher education has been given by Altbach (2006), Altbach, Reisberg and Rumbley (2009) and Kinght (2006). Commonly, they agree that internationalization is a response to globalization. These authors also agree that globalization is the inevitable flow of technology, economy, knowledge, technology, values, ideas people etc. across borders and institutions of higher learning in the contemporary world. According to Altbach (2006), internationalization involves specific policies and programs undertaken by governments, academic systems and even individual departments to deal with globalization. Furthermore, Altbach(2006) notes that globalization is beyond the control of another actor or set of actors. Similarly, Arum and Van de Water (1992) refer to internationalization as the multiple activities, programs and services that fall within international studies, international educational exchange and technical cooperation. Altbach, Reisberg and Rumbley (2009) indicate that the internationalization of higher education is notable for the multiple ways in which it has manifested itself around the world. These developments include mobility of people, programs, institutions, the rising prominence of research cooperation, evolving curricula as well as approaches to teaching and learning, an increasingly heightened sense of interconnectedness of higher education enterprise across the globe, and the growing pervasiveness of internationalization across institutions and broader systems of higher education.

During the last decade, international engagement has risen visibly on institutional and national agendas around the world (Rumbley, 2007). However, the necessity of internationalizing higher education presents many challenges at institutional and policy levels. To be meaningful and sustainable, internationalization requires access to some amount of resources (human and financial) as well as their effective deployment and management. For the world's poorest countries and most resource-deprived institutions, the opportunities to engage internationally can be extremely limited or fraught with worrisome trade-offs. In Africa, for example, the reliance on massive amount of foreign funding for research and other activities has long placed African universities at a disadvantage on several levels, not the least of which has to cope with a foreign donor's unpredictable and shifting priorities.

\subsection{The Research Function of Higher Education}

Several authors have analyzed the evolution of the functions of higher education over the years (seeClark, 1983, Perkins, 2006, Harman, 2006). All agree that over the last half century in industrialized countries, the functions of higher education institutions have been three-fold: teaching, research and scholarship and service. Harman (2006) argues that each of these functions is undergoing change. According to him, teaching has been usually defined mainly in terms of under graduate on- campus instruction, but in recent years this definition has required some adjustment to 
include postgraduate instruction, distance education (electronic means of education), various specialized roles as well as research training in the form of supervising research students who under take projects.

The terms research and scholarship have usually referred to uncovering or generating new knowledge, or solving theoretical problems. As research and scholarship have increased in importance, so have various elaborations in definitions have been introduced, including R\& D activities. Service has usually been defined to include internal service within higher education institutions, but more recently the meaning of service has been expanded to include consultant activities.

According to Harman (2006), within many universities there is an ongoing debate about the balance between teaching and research activities, the possible contribution that research makes to high quality teaching and whether research activities are best located in academic departments or research centers. Despite this, however, research is increasingly regarded as being a vital importance in modern universities and the idea of Research University is dominating. In the early 20th century, the idea of a research university has spread with a focus on primarily basic research and research training. There is also some commitment to applied research, but little to developmental research.

Today, there is a rising recognition of the importance of science and technology in economic development. Due to this, governments have been drawn into playing increasingly important roles in funding university research and in deciding on overall research directions and priorities. Two trends are dominant in research funding by governments. One is through annual grants allocated by governments to universities primarily to support their teaching tasks. The second is through the creation of specialized funding councils or agencies, and for more strategic and competitive approaches to allocations.

Like in all other continents on the globe, higher education is being recognized as a key force for modernization and development in Africa (Damtew Tefrra, 2006). However, Damtew Teferra (2006) argues that the central reality of African higher education is severe financial crises at the beginning of this century. Although governments pay the lion share of the budgets, the rest, particularly research is funded by international donors through research cooperation. According to Knight (2006), internationalization strategies in higher education can be observed at various levels, but at institutional level two dimensions can be used to identify program strategies. One is the academic program level, whose strategies can include such activities as student exchange programs, visiting scholars, study abroad programs and international students. The second is research cooperation which includes joint research projects, international conferences, publication of articles/papers, research exchange programs etc. Applied to Africa, including Ethiopia and Tanzania, access to resources is important to put these strategies to practice and that is why international research collaboration has become vital.

\subsection{Aid Effectiveness Debate}

Development aid got a lot of attention since the implementation of the best-known aid program, the Marshall Plan in war torn economies of Europe after World War II (Mavrotas, 2009). As the consequence of war, Europe confronted with a critical shortage of capital and physical infrastructure. In 1947, the United States responded by declaring the European Recovery Plan commonly called the Marshall plan. Under this plan, the US poured 13 billion dollars into Europe, and indeed assisted in European recovery.

This logic is applied in the modern development aid discourse, but it considers neither the size of aid needed nor the conditions which need aid in developing countries. Klees (2002) argues that Europe was already developed with an educated workforce; it only needed to rebuild the physical infrastructure destroyed by war, but the Marshall plan received about 8 times as money as ODA receives today.

Even then, there is a controversy on aid effectiveness particularly in the economic sphere. Hansen and Trap (2001), Roodman (2004) and Dalgaad et al. (2004) established a positive impact of aid on development where as such scholars as Bonne (1996), Easterly (2006) and Moyo (2009) argue that aid is ineffective and encourages dependency. Burnside and Dollar (2000) express that aid might work but only under favorable political and institutional conditions. Scahs (2005) has the opinion that aid is a moral obligation for developed countries and that it must be doubled. There are some particular studies with respect to aid effectiveness in education (see Michaelowa, 2004, Michaelowa and Weber, 2007, Dreher, Nunneenkapm and Thiele, 2008). Overall, these studies indicate that aid has positive 
impact on education. Michaelowa and Weber (2007) focused on the added value of aid to existing initial level of educational enrollment and completion while Dreher and Thiele (2008) investigated the overall effect of aid to education over several decades. Wolf (2006) included access to water and sanitation to education in his study of aid effectiveness. He concluded that the share of ODA that is provided for education, health, water and sanitation have positive impact on outcomes in these sectors.

\subsection{Research Training}

Countries vary widely in their support for graduate education, but there is widespread agreement that an expansion of doctoral education is a desirable goal worldwide, and many countries are in the process of expanding their capacity to provide training and are also looking for the best model to achieve this goal (Altbach, 2006). OECD (2002) indicates that Finland, Germany, Sweden and Switzerland recorded the highest number of doctoral graduates per capita in 2002. Brazil offers the largest collection of Master's and Doctoral programs in Latin America, awarded 6000 doctoral and 30,000 master's degrees in 2001. A comparative look at the production of new PhDs (Doctoral Degrees)in Science and Technology reflects favorably for the Scandinavian countries: for every 1000 inhabitants, 1.24 new doctorates were awarded in Sweden, 1.01 in Finland and 0.49 in Denmark -all of which are comparable figures for U.S. (0.41), and Japan (0.25). In terms of student enrollment, the US is second to China with 14 million students and roughly the number of doctoral students can go up to 400,000in all fields (Altbach, 2006).

The pattern of funding for doctoral education is the complex. For instance, in the US sources of funding for doctoral studies include the state governments, the federal government, and tuition fees paid by students, university endowments, philanthropic foundations, and businesses of several types. In all of Scandinavia higher education is basically funded by government or the public sector. In South East Asia, higher education is funded through privatization, corporatization of public universities as well as cost-recovery mechanisms. In China, there is a concentration of funding from central government to build world class universities and these universities educate majority of doctoral students (see Altbach, Reisberg and Rumbley, 2009).

\section{RESEARCH Methodology}

\subsection{Context: Tanzania and Ethiopia}

Tanzania earned its independence in 1961 and it is located in East Africa. It has a population of about 35.9 million and a per capita income of about $350 \mathrm{USD}^{1}$. The economy is heavily dependent on agriculture, a sector identified as a cornerstone for growth and poverty reduction, as $70 \%$ of the population depends on agriculture for survival. HIV/AIDS, malaria and malnutrition remain a threat against all development efforts. There are approximately1.2 million adults living with HIV infection, and malaria is the main killer for infants and children under five years. Life expectancy at birth has stalled at around 50 years since the late 1980s. The demographic bulge of current and future students (54\% of Tanzanians are less than 20 years old) has led the Government to seek improved enrolment, graduation, and transition rates among the growing age-cohorts throughout the system. The Gross Enrollment Rate in higher and technical education in 2008 was $1.6 \%$, one of the lowest in the world. The scientific and technological capacity needed for Tanzania to reach its full economic potential is weak, there were 13 researchers for every 10,000 in habitants in 2006, and in 2005 less than $0.03 \%$ of GDP was invested in research. Since the year 2000, Tanzanian economy is growing fast at annual average rate of $6 \%$.Despite these changes, Tanzania remained one of the poorest in the world. However, it has formulated a development and transformation plan in the vision known as MKUKUTA and the achievement of high rates of economic growth through technology and innovation is the corner stone of the program.

Ethiopia, a country located in the Horn of Africa with surface area of $1.1 \times 10^{6} \mathrm{~km}^{2}$ has never experienced colonization in Africa except the Italian occupation (1938-41). According to the AAU's Inception Report (2009), Ethiopia's population numbered 75 million, with growth rate of 3\% per year and having about 80 ethnic groups with diverse languages and culture. The United Nations

1 World Bank Report No 38820, Tanzania 
Development Program's human development index (2009) placed Ethiopia 171 out of 175 countries in terms of poverty, with $98 \%$ of the population earning less than US \$2 per day. The 2007 census showed $86 \%$ of the population living in rural areas, and $55 \%$ to be under the age of 15 years. Over the past decade, Ethiopia has issued several policy and planning documents to guide its development and to achieve the Millennium Development Goals. These are the Sustainable Development and Poverty Reduction Program (SDPRP) for the period 2002/03-2004/05, a Plan for Accelerated and Sustained Development to End Poverty (PASDEP) 2005/06-2009/10, and the on-going five-year development plan entitled Growth and Transformation Plan (GTP). During the PASDEP period, annual economic growth reached $11 \%$. The GTP anticipates maintaining Ethiopia's rate of economic growth at the very least; and aims to double it by 2014/2015 as progress toward moving Ethiopia into the status of a middle-income country by 2020 (AAU Block Grant Application (2009).In 2011/12, the Gross Enrollment Ratio in Higher Education reached 9.5\% down from less than $1 \%$ at the beginning of the millennium.

\subsection{Institutions: AAU and UDSM}

Addis Ababa University (AAU), known to be the oldest of the Ethiopian universities, was first established in the premises of the late Emperor Haile Selassie. It began operation in 1950 with the name of University College of Addis Ababa with 71 undergraduate students and 9 expatriate faculty members. Since then, the university has been changing in all its aspects of size, quality and the services it is providing to the Ethiopian government and people. Today, AAU enrolls over 50,000 students. Of this total, 11,300 are post graduate students of which 9,800 are Masters and 1,500 are $\mathrm{PhD}$ students in various disciplines. In 2011/12 academic year, AAU had 2,199 academic staff members and 4,739 support staffs. The composition of academic staff is highly skewed towards males where females comprise only $12 \%$. The professoriate comprises $36.6 \%$ and the rest are lecturers with less than a $\mathrm{PhD}$ level of qualification. In all its years, AAU has enjoyed collaborative research and training with international universities and research centers. Most prominent among these is the Swedish International development Agency (SIDA), which has always been a development partner of Ethiopia in education, capacity building and research.

The University of Dar-Es- Salaam (UDSM) is the oldest and most well established university in Tanzania. Established in 1961, the university has built high national, regional and international reputation. The University has three interconnected core functions:

- To transmit, through teaching, knowledge from one generation to another, and to meet the highlevel human resource needs of the Tanzanian society.

- To produce knowledge through research.

- To provide services to the community that address the country's existing and future social problems, through consultancy and outreach programs.

The University's vision of becoming "a reputable world-class university that is responsive to national, regional and global development needs through engagement in dynamic knowledge creation and application" has enhanced the realization of the three core functions. In 2011/12 UDSM had 1,254 academic staff members of which 377 (30\%) were PhD holders, 527 (42\%) were Master's holders and 350 (28\%) were degree holders. Female academic staffs constituted $24 \%$ of the total in 2010/11 $(\mathrm{N}=1,329)$. Total student enrollment in 2010/11 was 17,077 students out of which 2,646 (15\%) were post graduates. Out of the total enrolments, female students constituted $41 \%$ in the same year and $39 \%$ in post-graduate studies.

\subsection{Research Design}

The study was conducted using a comparative meta-analytic case study approach with time series design. Its comparative characteristics are based on its observations of two social systems or cases and the fact that it tries to determine how the two cases are similar or different in their use of SIDA support for research capacity building (see Warwick and Osherson, 1973). To the extent that this study uses the results of other studies or as far as it is the analysis of other studies, it is a meta-study (see Fagerlind and Saha, 1989). Addis Ababa University has been assessed by KPMG, a Swedish consulting firm, in 2010, 2011, 2012, three times since the agreement was signed in 2009. AAU has been reporting annually since the agreement was launched, but it provided the consolidated report in 2011/12. The focus of assessment by KPMG was financial auditing as well as evaluating 
administrative reforms. An additional mid- term evaluation was also carried out with two external consultants in 2011/12 as part of the project agreement. A similar procedure also existed at UDSM. The university has been producing several self-generated reports $(2010,2011,2012,2013)$ since the project in the current round started. A final evaluation was carried out by external consultants in 2013, of which the current writer was a member. For this study, it was decided to use these data which would provide accumulated information on SIDA support in the two universities over time. In Ethiopia, SIDA additionally supports doctoral programs at Haromaya University. In Tanzania, SIDA also supports graduate and post graduate programs in MUHAS and ARDI universities. In this study, the period of support considered is limited to 2009-13, and only AAU and UDSM are selected as our two case studies, because these are the two key institutions capable of providing sufficient information on issues under investigation.

\subsection{Instruments of Data Collection}

Document analysis of the previous studies provided invaluable information. These documents comprise annual and consolidated reports by the universities as well as reports prepared by external assessors. Annual and consolidated reports by universities are based on their surveys and education information systems. External assessments used interview guides (focus and individual), text and content analysis as well as taking field notes after observations. In case of UDSM, the current writer conducted interviews, document reviews as well as focus group interviews with various groups. In AAU, both KPMG and Mid- Term Evaluators reported that they used document analysis, interviews, group interviews and observations.

\subsection{Sample Selection}

AAU and UDSM are the highest beneficiaries of SIDA support in their respective countries. Due to this they were taken as the major focal institutions for this study. The sources of data for external assessments in both universities were members of the senior management (presidents, vice presidents/vice chancellors, Deputy vice chancellors, directors of research, directors of finance, academic staff members (student supervisors), deans, department heads and students. Internal visits were conducted in units that were designated for superior performance or where problems were encountered. This was to get complete information. Thus, in UDSM more than 75 individual interviews and 10 focus group discussions were reported. In AAU, 5 focus group interviews involving 45 people and 30 individual interviews were reported. KPMG administrative assessments have taken place almost every year since 2010, 2011, 2012 and they also used individual interviews, group interviews as well observations. All reports from each of the assessments were received for this study due to the special involvement of the researcher in both programs at the universities. At AAU, he was a Director of External Relations, facilitating such relationships and in UDSM he was a member of the external assessment team.

\subsection{Data Analysis}

Constant comparative method was used for data analysis. For each university, the types of reports to be used were identified. Following this, each of the reports for the cases was studied. Since these reports cover many details over the years, most important parameters or constructs were identified and information was arranged in that order. Analyses of trends from these reports were completed for each case. Following this, one-singe-case analysis was juxtaposed and compared with the other case to reach at the overall conclusions. It may need to be clear that the equivalence of concepts in qualitative study is relative and in this study not all constructs may be fully similar. We tried to make sense out of the available data although there can be some limited deviations in terms of the unit of observations.

\section{MAJOR FINDINGS}

\subsection{Framework for Research Capacity Building}

\subsubsection{Mainstreaming Research Policy}

Addis Ababa University (AAU): SIDA entered into agreement with Addis Ababa University to support graduate expansion, research and academic reforms for a period of five years, the first phase of which extended from July 2009 - December 2011. The total amount of grants for this phase amounted to 82.9 Million SEK. AAU has requested 74 MSEK for the year 2012-14. The goal of the project is to 
strengthen the capacity of Ethiopian higher education and research to meet the poverty reduction strategy of the country by supporting $\mathrm{PhD}$ program expansion at Addis Ababa University. The overall objective of the project is to develop and offer multidisciplinary graduate programs in all relevant fields. The project had the following specific objectives to: (1) launch in-house PhD programs; (2) establish centers of excellence, and (3) improve library services and enhance research facilities commensurate to the existing and envisaged $\mathrm{PhD}$ programs. The project was executed under the following major headlines: Graduate programs and research, Administrative and academic reform, integrated budget and finance information system (IBFIS) and Graduate library expansion.

University of Dar-Es-Salam (UDSM): Swedish support with Tanzania in research dates to 1977 when research was given to a national research Council (UTAFITI) now COSTECH. This initial support focused on individual projects, but since 1995 it was shifted to institutional support with UDSM as the core institution. Since this period, SIDA supported 43 projects amounting to SEK 340 Million. The total number of students has grown from 3,300 to 21,000 and SIDA's support represented $15-20 \%$ of UDSM's total budget and $85 \%$ of all research support at UDSM. Support has been provided for five agreement periods since 1994 and the current agreement which is the focus of this support has three basic objectives: (1) university reform and management, (2) research facilitating activities, and(3) research training. The total amount of funds for 2009-13 was 138,310,000SEK. For 2009-11 the total amount allocated was $85,910,000$ SEK.

In summary, the objectives of SIDA support in AAU and UDSM are similar. They focus on (1) research training, (2) creation of an enabling environment for research training including institutional reforms and (3) increasing the analytical capacity of these countries through research. In both countries, similar amount of funds has been allocated for two of the biggest institutions, although allocations are bigger for UDSM than AAU. Both Universities differ in the experience they have worked with SIDA in research collaboration with UDSM having a longer experience. However,

\subsubsection{Funding Research}

University of Dar-Es-Salaam (UDSM): The government remains the main source of general funding for universities. In 2010/11, the total approved budget of UDSM was 65.7B TZS. The proportion of the total released budget out this approved budget was $84 \%$. This means there was a gap between the approved and released budgets. Donors have continued to support the university operations and fill this gap, largely in areas of training, research and capital development. The best data on financial performance in UDSM are found in Facts and Figures, and it indicates that donor budget to research and training from the total donor operating budget in UDSM ranges between 100\% in 2009/10 and $74 \%$ in $2010 / 11$. In the same year, the total amount of donor operating budget constituted $42 \%$ of the total operating budget ( 82.05 billion TZS) at UDSM. The donor to government ratio in operating budget was 74\%. It was reported that the proportion of budget allocated by donors for research and training out of the total operating budget ranged between $16 \%$ in $2007 / 08$ to $43 \%$ in 2009/10. In $2009 / 10$ donors' support was totally devoted to research and training, but in other years it has also gone to capital development. The government budget is allocated to universities in three forms: salary, infrastructure and other costs. Funds for research come from other costs (OC) budget line and it is the responsibility of each university to decide the amount. UDSM has a budget line for research, but the amount varies from year to year and is small. As already indicated, there is heavy dependence on external donors both for research and capital development. In the following table the sources of external support are summarized at UDSM.

Table1. External Support to UDSM (TZS) 2007/08-2010/11

\begin{tabular}{|l|c|c|c|c|}
\hline SOURCE & $2007 / 08$ & $2008 / 09$ & $2009 / 10$ & $2010 / 2011$ \\
\hline Carnegie [USA] & $1,364,966,000$ & $1,049,000,000$ & $1,625,000,000$ & 0 \\
\hline Rockefeller & $51,205,000$ & 0 & $370,000,000$ & 0 \\
\hline $\begin{array}{l}\text { World Bank } \\
\text { Support }\end{array}$ & 0 & $5,274,000,000$ & $25,648,407,500$ & $23,024,621,724$ \\
\hline NORAD & 0 & $3,150,000,000$ & $3,150,000,000$ & $3,150,000,000$ \\
\hline SIDA & $4,950,045,000$ & $3,650,000,000$ & $2,169,592,244$ & $3,950,000,000$ \\
\hline NUFU & $577,676,000$ & $765,000,000$ & 0 & 0 \\
\hline REDET & 0 & 0 & $1,478,509,380$ & $1,642,691,000$ \\
\hline DANIDA-UDBS & 0 & 0 & $3,036,092,400$ & $3,036,092,400$ \\
\hline $\begin{array}{l}\text { TOTAL } \\
\text { SUPPORT }\end{array}$ & $\mathbf{6 , 9 4 3 , 8 9 2 , 0 0 0}$ & $\mathbf{1 3 , 8 8 8 , 0 0 0 , 0 0 0}$ & $\mathbf{3 7 , 4 7 7 , 6 0 1 , 5 2 4}$ & $\mathbf{3 4 , 8 0 3 , 4 0 5 , 1 2 4}$ \\
\hline
\end{tabular}


The above table shows that UDSM is supported by various donors including Sida. In 2010/11, Sida provided 3,950MTZS to UDMS, and this was $11 \%$ of the total donor support and $4.8 \%$ of the total operating budget of the university. Similarly, Sida support to UDSM in 2008/09 amounted to 3650 MTZS, which made $26 \%$ of the total donor support and $15 \%$ of the total operating cost for this year. During interviews, it was from these perspectives that the leaders of UDSM from top to bottom requested the continuation of Sida support.

Addis Ababa University (AAU): Like UDSM, the government remained the main source of funding for AAU. The university reported that its budgetary support has now almost tripled from about 200 Million Birr before the agreement period (2007/08) to 500 million Birr in 2010/11. It has also indicated that the budget for research has increased substantially although it does not address by how much. AAU has started collecting data on donor support, yet it does not have a well consolidated directory. A temporary list indicates, however, that the university has relations with donors from France, Germany, Italy, Norway, USA and others. The French Project for instance is financing a project entitled, "Reinforcing the Capacities of Addis Ababa University", with a total budget of 2 million Euro. The project has four components, Water and Development, Food Security, Urban Development program and an IT PhD Program. Similarly, Italy finances various educational and research endeavor at AAU through the postgraduate program component of Italian contribution to the Education Sector Development Program (ESDP) in Ethiopia. The total budget of the Post Graduate Program Component is 2.67 million Euros, equivalent to birr 60 million. The Ethiopian Institute of Water Resources, which is a collaborative endeavor among AAU, the University of Connecticut (UConn) and Alabama A \& M University, both in the US, aims to solve the shortage of trained human resource in water resources in Ethiopia. The first five years of budget of the Institute, which is seven million USD (120 Million Birr) has been earmarked from the American Council on Education/Higher Education for Development (ACE/HED). There are also various partnerships and collaborative projects that AAU has established with Canadian, Norwegian, German, Spanish and other donor countries, the total volume of which is close to ETB 45 million.

In summary, respective governments remained the sole sources of financing of higher education in both universities. However, research funds continue to depend on donors in both universities since the allocated fund for this function is extremely very small. A contribution of SIDA is also that it has served as a catalyst to attract funds from the institutions. It is interesting at the same time to observe that both universities are not sure of their donors for lack of data.

\subsubsection{Research Infrastructure}

University of Dar-Es-Salaam (UDSM): UDSM reports that SIDA has contributed greatly to research infrastructure. Within this programme one of the major foci was e-journal access and library development. It was reported that some subprograms like Library Support, Food Security, Rural and Urban Infrastructure Development and Marine Sciences have acquired major equipment and facilities. This includes journals, databases, computers, Internet (university library), laboratories, ICT infrastructure and automation of student record information system. The university admits that some inadequacies still prevail in research infrastructure. This is attributed to the large body of postgraduate students and academic staff using same research facilities. Consequently, it was reported that laboratories, libraries and other resources for postgraduate students are insufficient. With SIDA funds, the library reported that it has subscribed forty-five (45) electronic journal databases for 2013 to be used by all universities, successfully negotiated for use of e-resources for 98 institutions, selected and customized the Open Journal Systems (OJS) for the Tanzania Journals Online Database and digitized 13 journals. In summary, research facilities serve all the university communities of these institutions and this has put them under heavy pressures of use.

Addis Ababa University (AAU): AAU planned to strengthen graduate libraries in all campuses particularly those dedicated to $\mathrm{PhD}$ programs. These would be linked with computer terminals, and will have access to a wide variety of electronic databases. Through SIDA support, the graduate library has been strengthened by availing 49 electronic databases with a wide range of current and relevant research journals and books for researchers, academic staffs and students. In addition, more than 1,883 books were purchased for different Ph.D. programs. Books are received, catalogued and distributed to different branch libraries. Besides 141 computers have been acquired and being utilized 
in the different branches of the library. A small reference library has been established at the Southern campus for PhD students. Lack of efficient IT support has been a challenge for the optimal utilization of the electronic materials. AAU has also acquired laboratory equipment, chemicals and communication facilities worth 36 million ETB in 2010. The University floated an international competitive bid as per the standard bidding procedures of the Public Procurement Agency of Ethiopia in three lots for the purchase of 86 Scientific Laboratory Equipment, 19 Audio Visual Equipment and several chemicals in May 2010. Accordingly, 12 companies drawn from Singapore, India, Italy, UK and Belgium submitted their bidding proposals. As the final assessment of the bid documents indicate, the items were procured from ten companies located in different countries. However, AAU has not been able to establish a core laboratory and maintenance center as planned.

In summary, SIDA funding in both universities seems to have firmly put in place research infrastructure. Although enormous amount has been devoted to this part of the cooperation, it seems that more is required to satisfy the increasing needs of graduate education. A good example is the need at AAU to establish core laboratories. In UDSM, similar views have been expressed on the need to have SIDA support continued to meet demands for infrastructure.

\subsubsection{Integration of Gender}

University of Dar-Es-Salaam (UDSM): UDSM has a gender office and policy. The university follows affirmative action to prioritize women when the situation so demands. Regarding selection of female students, official documents indicate that the proportion of female students admitted remained stable and was on average 39\% during the period from 2006 to 2011. Over the same period, however, the portion of female finalists at undergraduate level has been increasing from 36\% in 2008/09to a recordhigh of $42 \%$ in 2010/11. Data also indicate that the number of postgraduates has been increasing with the portion of female finalists fluctuating between $31 \%$ and $37 \%$ in the period under review. Sida supported postgraduate programmes have contributed to narrowing the gap between female and male enrolments at UDSM although that gap is still wide. A total of 283 students were admitted to various programmes supported by Sida during the current agreement period under consideration. Of this, 78 (28\%) were female students. During the same period a total of 43 students completed their studies. Out of the graduates, the total number of female students was $11(26 \%)$.

Addis Ababa University (AAU): Gender issues are managed at AAU by the Directorate of Equity which comprises Gender and HIV/AIDs.AAU launched the graduate female scholarship scheme to raise the number of female students in its graduate programs. Accordingly, the University management approved an annual 200 graduate scholarships to female students. Following a media announcement in July 2010, for instance, over 4000 applicants applied and 150 talented female candidates for graduate studies were provided with scholarships. The stipend for the candidates was paid from the SIDA Block Grant. In 2011, the University has continued the offer and 200 female students have been granted the scholarship. It is interesting to note that the Scholarship in 2010 has raised the ratio of female students in the graduate programs from 10 to 15 percent. Similarly, the scholarship in 2011 has raised the female graduate student population to 19 percent.

In summary, both universities have put in place active gender policies in research. The number of females joining post graduate studies is growing in both universities due to scholarships. But, it is still a lot of gap to be filled in this respect. AAU also uses SIDA grants to support students will special needs and disabilities in the graduate programs.

\subsection{Implementation of Research Capacity Building}

\subsubsection{Instituionalization of Reseasch}

University of Dar-Es-Salaam (UDSM): UDSM has developed research policy, concept notes and agendas for research. The second edition of the research policy and its operational procedures was issued in 2008. Prior to the current document, the first edition of the research policy was issued in the early 1990s. The new research policy of UDSM is formulated within the context of the wider vision and mission of the university. UDSM aspires to become a world-class centre of excellence in research. Key strategies to implement the policy revolve around strengthening research management, sourcing funds and quality management. In UDSM research is facilitated through structural reforms, training and small grants. The use of publications for promotion serves as the main procedure or tool for facilitating research. In UDSM, student supervision, administrative rewards, participation in local 
and international conferences, memberships in professional associations are also influenced by research records.

The university has made significant structural reforms particularly since 2011. Before 2011, there were only two Deputy Vice Chancellors (DVCs): DVC for Academic Programmes and Research, and DVC for Administration. As of 2011, a third DVC was created for Research and Knowledge Exchange. The responsibility of this office is to promote research and community outreach programmes. Since the 1970s, this function was under the office of the Directorate of Research. UDSM extended the responsibility of the Directorate for Research to include Publications in 1998. The directorate is responsible for coordinating internal and external linkages on all matters related to research. There are also advisory bodies called Research Committees at various academic units of the university. The university senate has its own committee for research and knowledge exchange. UDSM gives a key role to the training of academic staff members in methods of proposal writing to facilitate their likelihood of winning research grants. Moreover, the Directorate of Research has a small grants programme for academic staff members, and a policy that requires staff members to publish in peerreviewed journals to get academic promotions.

UDSM has operational procedures to be followed in the process of developing a research proposal. After planning is over, the proposal is submitted to committees for review. These committees, known as Research and Publication Committees, are organized at departmental, faculty and university levels. They do assessments according to established criteria in the research policy. All research proposals are registered after approval. The Directorate for Research and Publications coordinates research project registration.

Addis Ababa University (AAU): The Higher Education Policy Proclamations 351/2003 and 650/2009 provided the overall context for policy making in Ethiopian universities. AAU formulated its first strategic plan in 2006/07 and launched a reform process known as "Business Process Reengineering" (BPR) in 2008. Business Reengineering Process was implemented from September 2009-December 2010. The BPR put in place a new governance structure where a vice presidency for research and post graduate schooling was established. The senate was designated as a supreme body for academic matters and established a research council. Faculties and schools were assigned the responsibilities of approving research projects and recommended for funding. Departments were made responsible for developing a strategic plan for research in consonance with the university plan. During this period, AAU developed several polices including research policy, but did not compile it into a hand book.AAU reformed the BPR in 2011 and research was put under a Vice President for Research and Technology Transfer. The Directorate of research was made responsible for research management. Both the previous senate legislation of 2007 and its revised version of 2013 establish research and publication as main requirement for staff promotion. Unlike UDSM, AAU does not have a staff training program in proposal writing although there is a small research grant for young academic scholars.

Overall, it possible to observe that post-SIDA funding, both institutions went through the same procedures of reforms. Both universities developed research policies and procedures, clear line of management structures, research incentives (as means to promotion) and facilitation mechanisms. The difference is that AAU has not developed a research policy handbook and did not use staff training as a facilitation mechanism for research capacity building.

\subsubsection{Results Monitoring and Management}

University of Dar-Es-Salaam (UDSM): Three review practices are considered as results-basedmanagement (RBM) mechanisms at UDSM: quarterly review reports, annual review reports and quality assurance reviews. Quarterly review reports are required from each academic unit to present its performance to the office of the Deputy Vice Chancellor for Academic Affairs. Annual review reports refer to practices of reporting performance on yearly basis while quality assurance reviews are appraisals carried out by the Office of Quality Assurance. The aim of UDSM is to use RBM as a general management tool, but full transition towards this system has not been achieved. For instance, a results framework with performance indicators has been developed to enhance measurability in Sida support, but it has not been used right from the beginning. The system, including Sida support, lacks clear performance indicators, baselines and targets against which progress can be measured. 
Addis Ababa University $(A A U)$ : In this agreement period, it was the log framework which was in use at AAU. As such no Performance Management Plan was prepared and Results based Monitoring (RBM has not been applied in AAU. Because baseline and targets were not defined together with performance indicators, it was not possible to objectively measure progress. Results were reported on quarterly and annual basis and it might be difficult to delineate SIDA impact.

Overall, the introduction of RBM seems very far from happening in both institutions and there is no doubt that such conditions lead to difficulties to measure progress and improvements in the support program and to reporting. As it is just now, no targets and baselines were established at the beginning of the two projects and the desire to use RBM is an after-fact. Since RBM requires capacity building, such measures may need to be integrated in project planning. Due to this, reporting of results is poor in both institutions.

\subsubsection{Intellectual Property (IP) and Outreach Management}

University of Dar-Es-Salaam (UDSM): A good example concerning the management of intellectual property is found in UDSM. There is an intellectual management office created to advise the university on issues related to copy rights, patents, plagiarism etc. The first UDSM Intellectual Property Policy was issued in 2008. UDSM owns intellectual property that is made or designed by its members. Ownership of externally sponsored research is governed by the terms of agreement as approved by UDSM. The researcher can also have the right to ownership in case UDSM opts not to pursue IP protection. In UDSM, some units are research based and this means they give more time to research and consultancy. Others are teaching-intensive and academic staffs are required to dedicate $75 \%$ of their time to teaching. Consultancy is an institutionalized system where using university time and property are charged from the consultant. A knowledge exchange office is newly created to promote the utilization and commercialization of research.

Addis Ababa University (AAU): AAU's 2011 structural reform brought about a Directorate for Technology Transfer as a responsible body to coordinate and facilitate the planning and development of intellectual property rights in collaboration with relevant institutions. Up until the final midterm evaluation was carried out in 2011, assessment reports indicate that no such policy and office have been operational. The previous senate legislation of 2007 indicates for AAU that research institutions are expected to devote $75 \%$ of their time on research and outreach programs, whereas, teaching departments were expected to devote $75 \%$ of their time on teaching. The 2013 senate legislation, however, demands a 50/50 partition of academic staff time between research and teaching considering the new focus on postgraduate education. AAU has also recognized the right to consultancy by academic staff. There is a directorate of community services which is charged with this responsibility although the practical action of the directorate by far less visible.

In summary, both institutions have given due recognition to intellectual property management. However, UDSM is more active than AAU since it has an exclusive office and directorate for these tasks. It has also developed clear polices which is being currently in use. On the other hand, both universities recognize the right to consultancy in a balance with teaching and learning. In AAU, there is a tendency to equalize teaching and research taking its new role as a research university.

\subsubsection{Grants Management}

University of Dar-Es-Salaam (UDSM): At UDSM, it is generally known that there are two levels at which research grant applications can be submitted. The Directorate of Research and Publication centrally submit some proposals to external funding institutions while others are submitted by individual researchers in academic units or departments. The exact numbers of applications submitted are not known, but attempts to get research grants are apparent. For instance, the Directorate of Research and Publication has submitted five project proposals in 2013. The following table illustrates efforts to submit research proposals, but the number of research projects completed at UDSM has dropped to 162 during 2010/11.

Table2. Number of research projects completed and in progress at UDSM (2006/07-2010/11)

\begin{tabular}{|c|c|c|c|c|c|}
\hline \multirow{2}{*}{ UDSM } & \multicolumn{4}{|c|}{ Year } \\
\cline { 2 - 6 } & $\mathbf{2 0 0 6 / 0 7}$ & $\mathbf{2 0 0 7 / 0 8}$ & $\mathbf{2 0 0 8 / 0 9}$ & $\mathbf{2 0 0 9 / 1 0}$ & $\mathbf{2 0 1 0 / 1 1}$ \\
\hline Completed and ongoing & 275 & 258 & 247 & 247 & 162 \\
\hline
\end{tabular}

Source: UDSM (2012). Facts and Figures 2011/12 
Addis Ababa University (AAU): One of the agreements reached between AAU and SIDA in the 2010 project period was the launching of thematic research. Accordingly, the various faculties, colleges and institutes of AAU were invited to come up with thematic research proposals. The University has now, for the first time in its history, outlined its thematic research areas based on national interest. The thematic research areas were identified following an extensive consultative process. The goal is to make research meaningful and outcome oriented by avoiding fragmented and isolated research. Over 70 proposals that were submitted following a call have been grouped into 15 major thematic research areas bringing together researchers across departments, schools and colleges. The thematic research proposals were first reviewed by a panel of assessors and improved based on the comments of the reviews. Most of them were then provided Birr 300,000 from government budget as seed money to start the projects. The Government has now allocated about 19 million birr for the conduct of the thematic research. Like in UDSM individual researchers also apply for external funds, but it is not usually known by the administration.

In summary, in both AAU and UDSM individual applications can be internally or externally submitted. But, the extent to which these are known to the universities is very low. Individuals in both universities can apply to governmental research commissions provided that their areas of expertise are relevant to calls. AAU is different because it has a well-organized thematic research program. However, by admission of AAU, transparency of fundraising projects has been a great question.

\subsubsection{Support Structure}

University of Dar-Es-Salaam (UDSM): Research support in UDSM is institutionalised. The Deputy Vice Chancellor for Research and Knowledge Exchange reports to the Vice Chancellor whereas the Director of Research reports to DVC (Deputy Vice Chancellor). Other formal structures (committees) also exist. Researchers develop projects and look for potential funders by themselves. Some of these proposals win funds while others may not. Moreover, UDSM has capacity building programmes in which it provides trainings in how to develop research proposals for winning funds. Research methodology courses are strengthened through reviews and updates to inculcate research culture among students and staff. University professors are promoted to higher academic ranks through research and publications in peer reviewed journals. UDSM reports that it has high retention of academic staff. According to university leaders, one reason why UDSM could retain its academic staff relates to the improved capacity of staff members to formulate high quality proposals and win projects. According to data from UDSM, consultancy projects grew from 45 in 2005/06 to 94 in 2011/12. More research grants are coming to the university and UDSM reported that consultancy revenues grew from 32.6MTZS in 2005/06 to 723.3MTZS in 2011/12. The volume of proposals increased significantly because of the capacity building programmes supported by Swedish International Development Authority (Sida).

Addis Ababa University (AAU): Like UDSM, SIDA support is transforming research as one of the most important components of university functions in AAU. AAU has a clear line of management for research. Like UDSM, AAU researchers also apply to external sources for funding, but usually unknown to the central administration. Internally AAU had developed research groups in themes and money is provided from SIDA support and the government (seed money). Promotion of academic staff also depends on research out puts. Unlike UDSM, AAU does not attract academic staff mainly due to low salaries even in comparison to Sub Saharan African standards. Unlike UDSM, training programs in research proposal development and strengthening of research methodology courses by way of training academic staff have not been reported in AAU.

\subsection{Researcher Training}

\subsubsection{Selection and Admission of Research Students}

University of Dar-Es-Salaam (UDSM): At UDSM, selection is formal, competitive and transparent. It involves the following steps: programmes are publicly announced, students apply on the basis of the announcements and departments select students considering the available places using grade point averages (GPAs) as cut-points. Applications to MA programs usually exceed the available places. Thus, the use of GPA as the main criterion is obligatory. For Ph.D. students, the availability of a research supervisor is critical. The challenge for UDSM is not selection, but it is to get all selected 
students to register because most complain about inadequacy or lack of funds. According to data released by UDSM, unit cost per student varies from program to program, but the average grand per student unit cost for an 18-month Master program is 21,028,333.33TZs. The highest grant per Master student for an 18-month program is 26,520,000TZs and the lowest 14,632,500TZs. A stipend for a Masters student is 500,000 TZS/month. Similarly, for 24 months Masters by thesis program, the average grant per student is $32,675,000 \mathrm{TZs}$. The implies that universities need to assess the adequacy of their funds to local postgraduate programs, and need to essentially improve their effectiveness in the recruitment of students so that they are joined by all selected candidates. Post graduate student enrolments in UDSM from 2008/09 to 2010/11 were 2,697; 2,592 and 2,646 respectively.

Addis Ababa University (AAU): Following the huge expansion of higher education institutions in Ethiopia, AAU has been entrusted with the mission of building the human resource needs of these emerging universities. Consequently, AAU has been accepting graduate applicants primarily from these universities as has been agreed with the Ministry of Education. In principle, AAU selects its post graduate students with public announcements, written exams and/or interviews on competitive basis. Procedures are also elaborated in the senate legislation. Departments are the major responsible bodies for admissions and selection. In the reporting period 2009, 2010 and 2011, the School of Graduate Studies (SGS) admitted 2941, 3547 and 3122 (Total 9610) masters' applicants respectively. It has also admitted 438, 347 and 312 (Total 1097) PhD applicants. Self-sponsored applicants have been admitted once the applicants from the emerging universities are placed and the need of other public institutions is fulfilled. For few years, this has been a source of grievance for private applicants as the space left for them had been minimal. Recently, however, more and more self-sponsored students are getting access to the graduate programs even at PhD levels. In 2010, for instance, 26 selfsponsored PhD students have got admission. Like in UDSM, students have expressed the shortage of funds in pursuing PhD programs. The government responded by providing by housing allowances to $\mathrm{PhD}$ students from universities.

In summary, both UDSM and AAU follow open, formal and competitive selection and admission of procedures for graduate studies. However, AAU's prearranged admission of university academic staff members is different from UDSM. Although, this is primarily meant for meeting the demands of emerging universities, the possibility that low caliber candidates join the $\mathrm{PhD}$ programs exists. In both universities, availability of funds for students are highly influential to decide on whether to join these programs. In both universities, admissions are increasing in a dramatic fashion.

Overall, it is possible to visualize that $\mathrm{PhD}$ outputs are low in number in both universities. In UDSM students started later than anticipated (around 2011), but in AAU the programs have taken longer than expected. However, since the number of admissions have increased in number, it is possible to see more graduates in the years ahead. One would also consider the long-time PhD programs usually require as compared to Master's program.

\subsubsection{Joint Training and Research}

Addis Ababa University (AAU): The graduate programs at AAU have expanded in several folds in the past few years. This has created an acute shortage of senior faculty that can handle courses and supervision of research activities. One of the strategies pursued to tackle this problem was the formulation of consortia with numerous partner universities abroad, mainly in Europe and the United States. Because of these collaborations, over 213 scholars (40, 105 and 68 in 2009, 2010 and 2011, respectively) were engaged as visiting professors, external examiners, and advisors in the PhD Programs. The visiting scholars' scheme allows senior professors from partner universities to come to the University for four to six weeks and offer specialized courses especially to $\mathrm{PhD}$ students. The visiting professors came on average for a period of four weeks. Adjustments were made so that the students were available for block teaching for an intensive and interactive engagement. Inputs given from departments and program units indicate that this strategy has been enlivening the overall academic environment, in addition to the major contribution to mitigate the acute shortage of senior faculty members in some departments of the University. To the visiting scholars, AAU covers their travel and accommodation expenses and pays modest honoraria from the SIDA block grant.

University of Dar-Es-Salaam: In Tanzania funds are mainly used for collaboration with Swedish Universities. In quantitative terms, the centrality of Swedish collaboration can be concretely seen in joint publications. The most significant foreign collaborator of UDSM was Stockholm University and 
the third was Uppsala University. In 2011/12, UDSM published 298 journal papers, 170 conference papers and 134 research reports. Research collaboration with Tanzanian institutions is far from insignificant for many Swedish collaborators, too. In an interview, one coordinator emphasized the scientific outputs of the collaboration as well as the fact that SIDA funding enabled some research groups to apply for and win much larger EU projects. In the training process, the sandwich program having a variety of models is implemented based on the actors involved. Commonly, all Ph.D. students spent some time in Sweden, although that time varied from weeks to months. The Swedish support was mainly of three kinds: Thesis (co-) supervision, doctoral level courses, and use of advanced facilities. The efficiency of the sandwich model was, in many cases, eroded by the acute shortage of staff in UDSM. Although students' progress was fast during their visits to Sweden, Swedish supervisors as well as students frequently remarked that when in UDSM, many students slowed under heavy teaching and administrative load, with too little time left for doing their $\mathrm{PhD}$ research.

In summary, AAU and UDSM have used internationalization as mechanism to overcome the impact of shortage in academic staff to their PhD training programs. AAU invites visiting professors while UDSM uses sandwich programs which involve different formats. These programs involve course provision, student supervisions and use of advanced facilities. In fact, AAU's benefit in use of advanced facilities is not as high as UDSM. UDSM and AAU differ from each other in actual research collaboration. UDSM is involved with collaborative research with Swedish institutions while AAU is very much consumed with thematic-local research.

\subsubsection{Training Outputs}

University of Dar-Es-Salaam (UDSM): During the agreement period, UDSM has been active in the production of postgraduates. Overall, UDSM's postgraduate output has been 1,067, 771 and 846 from 2007/08-2010/11 respectively. Some Ph.D. capacity building efforts were initially aimed at employees of each institution, but after UDSM fell short of their quota, calls were extended outside the institutions. Even then UDSM struggled to encourage candidates to apply. Hence, in many programs doctoral students started around 2011, and it would be reasonable to expect many graduates in 2015-2016. Master's level (Graduate) training programs were other important capacity building components in UDSM. In some fields, the available pool of capable master's degree aspirants was not large enough to initiate postgraduate training. In most cases, however, there were no problems with getting a sizable number of applications for Master's programs and a grade point average cut-off was often used to select students.

Addis Ababa University (AAU): AAU is undertaking tremendous efforts to expand graduate continuing education which gives further opportunities of enrolment for self-sponsored students. In 2010 alone, AAU has admitted 1,381 graduate applicants for masters' studies. There are also students who are enrolled in the summer-in-service program. AAU is working to contribute to a government plan of producing $5000 \mathrm{PhD}$ and 20,000 masters' graduates in 10 years, from 2009-2018. This represents graduating $500 \mathrm{PhD}$ and 2000 masters' graduates annually. The University has graduated more than 2,387 masters and PhD students in 2010/11. Out of these, about 100 students were $\mathrm{PhD}$ graduates.

\subsubsection{Perceived Impacts of SIDA Grants}

University of Dar-Es-Salaam (UDSM): At UDSM, SIDA support has been perceived as instrumental in developing research capacity. Three benefits were mentioned: capacity building at advanced degree level, training in research proposal writing and dissemination of research results. Regarding capacity development at Ph.D. level, some in leadership positions at the university were trained with SIDA support. Concerning proposal writing, it was mentioned that highly trained professionals not only write competitive proposals, but also serve as trainers, reviewers, assessors etc. With dissemination, it was mentioned that SIDA support has been instrumental for publications and sustenance of scientific journals. Moreover, SIDA's contribution in research infrastructure and Swedish institutional support for complex academic issues that could not be managed in Tanzania has been recognized.

Addis Ababa University ( $A A U)$ : AAU also reported that the support of SIDA has been influential in the launch of new $\mathrm{PhD}$ and Master programs and increasing the number of candidates admitted into 
the programs. It has also indicated SIDA's support is improving the quality of the programs, and contributing to the academic and administrative reform processes. The support complemented AAU's big stride forward by offering block grants and regular assessment schemes that kept AAU on the right truck. It specifies about 19 such impacts that SIDA support brought about in the institution.

In summary, both UDSM and AAU report that SIDA's support contributed to expansion of research training, conducting of academic research, increased graduate student admission as well as to disseminate the results of research. In both cases, the Swedish support is reported to have contributed to the development of research infrastructure that might not be afforded by the two institutions.

\subsubsection{Utilization of Research Outputs}

University of Dar-Es-Salaam (UDSM): UDSM is playing active roles in promoting the application of research in society. Firstly, it has established a new knowledge exchange office. Secondly, it carries out dissemination workshops, publishes articles, books, pamphlets etc. For instance, the university has presented 198 conference papers, and published 323 articles in journals and 117 research reports in 2011/12. Several academic staff members (particularly in the social sciences) are advisors to government in policy making. The university proudly reports that working with the government is one of the best ways to reach the public at large. Apart from this, it is within the research policy document of UDSM to reach citizens with research results in languages that they can understand. According to interviews with the Director of the Research and Publication Directorate, UDSM translates research results into Kiswahili before they are sent or disseminated to the people. Researchers are responsible to present and discuss their findings with villages and village governments as well. Thirdly, the Directorate of Knowledge Exchange promotes innovation for use in industry by encouraging incubation, marketing and cluster initiatives. Fourth, research findings are presented to government as a piece of advice to policymaking by researchers, and fifth, researchers also discuss their results directly with villagers and village level governments.

Addis Ababa University (AAU): AAU has developed an office for university-industry linkage and technology transfer for applications of research in wider society. Among other things, this office is responsible to demonstrate and popularize technologies to societies at large. Addis Ababa University encourages its staff and graduate students to engage in meaningful research, publish their findings in local, regional and international journals, and present their research findings in international workshops and conferences. Publication of research findings in reputable journals is a major condition for promotion of the academic staff. The total number of journals in the university has now reached over 40. Most of these journals publish original works of the staff of the University and other researchers in the region and elsewhere. The AAU Library System has developed a database of more than 4000 thesis and dissertations produced by graduate students of AAU. This database is accessible online by the wider community. The Library is also serving other universities in the Country.

In summary, both universities have been working to integrate and own research into their activities. Firstly, they have formed appropriate channels of management. Secondly, they also work to apply knowledge in society using various mechanisms (publications, workshops conference etc.). UDSM's effort is different from AAU in applying knowledge in that research results are translated to local languages and discussed with village governments and villagers themselves.

\subsection{Implementation Issues Encountered}

At UDSM, delays in funding and long bureaucratic procedures are problems in research management. Substantive problems mentioned by students include delays in proposal defence, supervision, lack of finance, theoretical nature of the curricula, lack of courses in some programmes, shortage of facilities and inadequacy in the provision of research methodology courses. With reference to proposal defence, students emphasized the fact that it takes a long time until proposals are defended. Regarding finance, students expressed concerns about its insufficiency both for stipends and research. Some students were also critical of the theoretical nature of the curricula and the lack of knowledge in practice. Students have the view that facilities including computers, Internet and laboratories are not adequately available.

At $A A U$, lack of information flow (especially about funding of $\mathrm{PhD}$ research proposals), delays in procurement process, quality assurance and faculty shortage, monitoring and evaluation of $\mathrm{PhD}$ programs, failure to establish Centers of Excellence for multidisciplinary and interdisciplinary research, and failure to establish core laboratories and a maintenance center were reported. 


\section{SUMMARY AND DisCUSSIONS}

Unlike skeptics who doubt the effectiveness of development aid, our findings from AAU and UDSM indicate that the research capacity building incorporated in the SIDA agreements with the two institutions have been immensely contributing to research and research training in the two countries. As it has been already, indicated the two countries follow transformation plans called MUKUTULA and GTP in Tanzania and Ethiopia. Both have vision 2015 to transform their societies into middle income nations. These plans demand a trained human power to realize their visions. SIDA support in both institutions has achieved the following in terms of capacity building in research:

- SIDA support is related to creating clear research capacity building frameworks in both universities. Both AAU and UDSM streamlined research as one of the basic functions of universities which required attention at a higher level.

- In both AAU and UDSM there were instructional reforms leading to clear line of management for research, research policies and procedures, research incentives(as means to promotion) and facilitation mechanisms. The difference is that AAU has not developed a research policy handbook and did not use staff training as a facilitation mechanism for research capacity building.

- SIDA support has not been based on the use of results-based-management (RBM) and there is no doubt that such conditions lead to difficulties to measure progress and report improvements. It was observed that no targets and baselines were established at the beginning of the project and the desire to use RBM was an after fact. Secondly, universities have not developed RBM for their mainstream activities and there is no spill over and capacity building from the project itself in this area.

- Both institutions have given due recognition to intellectual property management. However, UDSM is more active than AAU since it has an exclusive office and directorate for these tasks. It has also developed clear polices which is being currently in use.

- AAU and UDSM recognize the right to consultancy in a balance with teaching and learning. In $\mathrm{AAU}$, there is a tendency to equalize teaching and outreach considering its new role as a research university. Thus, research is gaining ground in the transition of these universities from teaching to research.

- There is a clear indication that academic staff members are becoming more competitive both internally and externally with the introduction of SIDA funds. This is because there were capacity building programs particularly in UDSM and thematic research in AAU. In both cases, individual applications to external agencies are very well documented.

- SIDA support is transforming research as one of the most important components of university functions both in AAU and UDSM. Both institutions have a clear line of management for research. Like UDSM, AAU researchers also compete for external sources of funding (although not usually known to the central administration). Internally AAU had developed research groups in themes and money is provided from SIDA support and the government (seed money). Promotion of academic staff also depends on research out puts. Availability of research funds attracts staff in UDSM while AAU does not attract academic staff mainly due to low salaries. Unlike UDSM, training programs in research proposal development and strengthening of research methodology courses by way of training academic staff have not been reported in AAU.

- Both AAU and UDSM have put in place active gender policies in research due to SIDA support. The number of females joining post graduate studies is growing in both universities due to scholarships. But, there are still many gaps to be filled in this respect. AAU also uses SIDA grants to support students will special needs and disabilities in the graduate programs.

- Governments remained the main sources of financing of higher education in both universities. However, research continues to depend on donor funds in both universities since the allocated fund for this function is extremely very small. A contribution of SIDA is also that it has served as a catalyst to attract funds from the institutions.

- SIDA funding in both universities seems to have firmly put research infrastructure in place. However, there are still inadequacies in both universities. 
- Both UDSM and AAU follow open, formal and competitive selection and admission of procedures for graduate studies. However, AAU's prearranged admission of university academic staff members is different from UDSM. Although, this is primarily meant for meeting the demands of emerging universities, the possibility that low caliber candidates join the $\mathrm{PhD}$ programs exists. In both universities shortage of funds for admitted students is highly influential to decide on whether to join these programs.

- $\mathrm{PhD}$ outputs are low in number in both universities although Masters graduates are quite considerable. Ethiopia expects about $500 \mathrm{PhD}$ graduates per year over ten years, but the maximum production is about 100 from AAU. In UDSM, students started later than anticipated (around 2011), but in AAU the completion of programs has taken longer than expected. However, since the number of admissions have increased in number, it is possible to see more graduates in the years ahead.

- AAU and UDSM have used internationalization as mechanism to overcome the impact of shortage in academic staff to their $\mathrm{PhD}$ training programs. AAU invites visiting professors while UDSM uses sandwich programs which involve different formats. These programs involve course provision, student supervisions and use of advanced facilities. In fact, AAU's benefit in use of advanced facilities is not as high as UDSM. UDSM and AAU differ from each other in actual research collaboration. UDSM is involved with collaborative research with Swedish institutions while AAU is very much consumed with thematic-local- research.

\section{LESSONS LEARNED}

Development aid by itself did not resolve all problems for which it was intended. Outstanding implementation issues have intervened for achieving the anticipated outcomes. In AAU, delays in procurement process, lack of quality assurance, continued shortage of faculty, lack of monitoring and evaluation of $\mathrm{PhD}$ programs, failure to establish Centers of Excellence for multidisciplinary and interdisciplinary research, and failure to establish core laboratories and maintenance center were reported. In UDSM, delays in funding and long bureaucratic procedures are problems in research management. Substantive problems mentioned by students include delays in proposal defence, supervision, inadequacy of finance, theoretical nature of the curricula, lack of courses in some programmes, shortage of facilities and inadequacy in the provision of research methodology courses.

The continued prevalence of problems regarding research and research training suggests that African universities cannot continue to totally depend on foreign aid to build their capacity in research. After many years of receiving aid, both universities are still on a continued demand for more support to meet their needs. Agreeably, development aid may supplement the efforts being made, but complete change requires that both universities also need to generate their own resources. To the extent that globalization triggers foreign influences to which both universities have to respond, internationalization will be a feature that will continue to exist in both contexts.

\section{REFERENCES}

AAU (2011). SIDA ,Block Grant Project. Consolidated Report (200-11). Extension Request (201214).

AAU (2011). AAU Applications for SIDA Support. Final Document: AAU, Addis Ababa.

Altbach, P., Resiberg, L., and Rumbley, L.E. (2008).Comparative Higher Education: Knowledge, the University and Development. Center for International Higher education: Boston, Boston College.

Altbach, P. Resiberg, Rumbley, L.E.(2009). Trends in Global Higher Education. Tracking an Academic Revolution. Center for International Higher education: Boston, Boston College.

A.U. (2012). AU Outlook on Education Report. Continental report. Tunis: ADEA.

Clarck, B. (1983).The Higher Education System: Academic Organization in a Cross-Cultural Perspective: London: University of California press.

Dalgaard, C.J., Hansen,H. and Trap, F.(2004). "On the Empirics of Foreign Aid and Growth". The

Economic Journal. Vol.114, pp.191-216.

Dreher,A.,Nunnenkamp,P. and Thiele, R. (2008). "Does Aid for Education Educate Children? Evidence from panel Data, ETH Zurich, KOF Working Paper No. 146. 
Internationalization of Research Capacity Building in Africa: A Case Study of Swedish International Development Authority (SIDA) Support for Addis Ababa (AAU) and Dar-Es-Salaam (UDSM) Universities

Easterly, W. (2006).'The White Man's Burden. Why the West's Effort to Aid the Rest Have Done So Much ill and so Little Good. New York: penguin.

Fagerlind, I. and Saha.L.(1989). Education and National Development : Oxford: Pergamon.

Freemen, P. and Mohamedbahi, G. (2011).Reform and Expansion of Reform training at Addis Ababa University: Assessment of Progress under agreement 209-2001, Sida Block Grant.

Hansen, H. and Trap, F. (2001). "Aid and Growth Regressions'. Journal of Development Economics. Vol.64, pp.547-570.

Harman, G. (2006). "Research and Scholarship". In J. Forest and P.Altbach (2006). Internal handbook of Higher Education. Part One: Global Themes and Contemporary Challenges. The Netherlands: Springer.

Klees,S. (2002). World Bank Education Policy: new Rhetoric, Old ideology”. Internal Journal of Educational Development, 22, pp.451-474.

Knight, J. (2006). "Internationalization: Concepts, complexities and Challenges". In J. Forest and P.Altbach (2006). Internal handbook of Higher Education. Part One: Global Themes and Contemporary Challenges. The Netherlands: Spinger.

KPMG(2009). SIDA Report: Capacity Assessment of the Administration Reform at AAU University. Follow up 2009-2010.

- (2009). AAU Report PhaseI: Capacity Assessment of the Administration Reform at Addis Ababa University.

- (2009). AAU Report Phase II: Capacity Assessment of the Administration Reform at Addis Ababa University.

- (2010). SIDA Report: Capacity Assessment of the Administration Reform at Addis Ababa University.

Mavrotas,G. (2009). "Development Aid-Theories, Polices and Performance.” Review of Development Economics, 13(3), 373-381.

Michaelowa, K. (2004).Aid Effectiveness Reconsidered: panel Data Evidence for the Education Sector. HWWA Discussion paper No.264.

Michaelowa, K. and Weber,A. (2007). Aid Effectiveness in the Education Sector: a Dynamic Panel Analysis. In S. Lahiri (ed.): Theory and Practice of Foreign Aid. Amestrdam, pp.357-385.

Ministry of Education (2012). Education Statistics Annual Abstrcat. Addis Ababa:MOE

Moyo,D. (2004). Dead Aid: Why Aid is Nor Working and How there is a Btter Way For Africa. New York:Farrar, straus, and Giroux.

Perkin, H. (2006). "History of Universities". In J. Forest and P. Altbach (2006). International Handbook of Higher Education. Part One: Global Themes and Contemporary Challenges. The Netherlands: Springer.

Roodman, D. (2004). The Anarchy of Numbers: Aid, Development and Cross-Country Emprics. Center for Global Development Working Paper No.32.

Rumbley, L. E. (2007). Interview with Jane Knight: IAU Global Survey Report on Internationalization of Higher Education. CIHE Initiative. http://www.bc.edu/cihe/podcast/

Schmidt.E.(2006)."Higher Education in Scandinavia". In J. Forest and P.Altbach (2006). International Handbook of Higher Education. Part One: Global Themes and Contemporary Challenges. The Netherlands: Springer

Tefera, D. (2006). "Higher Education in Sub-Saharan Africa". In J. Forest and P. Altbach (2006). International Handbook of Higher Education. Part One: Global Themes and Contemporary Challenges. The Netherlands: Springer.

UDSM (2011). SIDA Cooperation with the University of Dar-Es-Salaam: Annual Progress Report (July 2010-June 2011). Dar-Es-Salaam: UDSM.

UDSM (2012).University of Dar-Es-Salaam-Sida Cooperation (2009-13): Institutional Progress Report. Dar-Es-Salaam: UDSM. 
UDSM (2013). UDSM-Sida Cooperation Program. Progress Report (July 2012-June 2013).

Warwick,D.(1973). Comparative Research Methods. Massachusetts: Prentice hall, Inc.

Wolf,S. (2006). Aid and Public Expenditure in Africa: Does Aid Increase the Efficiency of Public Service Delivery? Paper presented at the EIDER Conference on Aid: Principles, Polcies and Performance, 16-17 June, 2006.

\section{AUTHOR'S BIOGRAPHY}

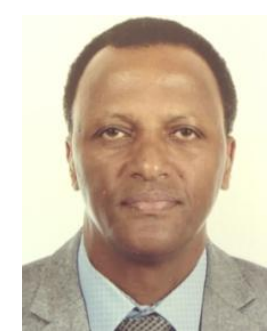

Teshome Nekatibeb Begna, is a $\mathrm{PhD}$ in International and Comparative Education from Stockholm University, Sweden. He was involved in Post-Doctoral Research in the University of Kassel, Center for Higher Education Research (UNCHER) in Germany. He served at Addis Ababa University, Ethiopia as Associate Professor and founded the Center for Comparative Education and Policy Studies. Dr. Nekatibeb has also worked in International Development for many years. He was a Technical Advisor for Monitoring, Evaluation and Policy Analysis for Academy for Educational Development in Ethiopia's BESO project. He also served as a Monitoring and Evaluation Senior Specialist for RTI- International in Jordan and as Senior Education Advisor for Creative Associates International in Afghanistan. Dr. Nekatibeb has served as a consultant for several international institutions including the World Bank, UNICEF, UNESCO, NORAD, Young Lives and KPMG both inside and outside Ethiopia for several years. 